\title{
Reliability of Energy Systems in Far North
}

Dmitry V. Prokhorov*a, Valeriy A. Prokhorov ${ }^{\mathrm{b}}$ and Nikolay A. Petrov ${ }^{\mathrm{a}}$ "Institute of Physical and Technical Problems of the North SB RAS 1 Oktyabrskaya, Yakutsk, 677891, Russia

${ }^{b}$ North-Eastern Federal University 58 Belinsky Str., Yakutsk, 677000, Russia

Received 08.08.2017, received in revised form 20.09.2017, accepted 04.12.2017

A complex analysis of accidents in power supply systems in the conditions of the Far North as complex technical systems is given. Based on the accidents description analysis, causes of failures, energy systems recovery time distribution, were analyzed. The recovery time as a measure of reliability is suggested to be used to estimate failures severity.

Keywords: accident, water supply, recovery time, reliability, failure, energy system of the Far North, heat supply, electric power supply.

\section{Надежность систем энергетики Крайнего Севера}

\author{
Д.В. Прохоров ${ }^{a}$, В.А. Прохоров ${ }^{\tilde{\sigma}}$, Н.А. Петров ${ }^{\mathrm{a}}$ \\ а Институт физико-технических проблем Севера \\ им В.П. Ларионова СО РАН \\ Россия, 677891, Якутск, Октябрьская, 1 \\ ${ }^{\sigma}$ Северо-Восточный федеральный университет \\ им. М.К. Аммосова \\ Россия, 677000, Якутск, ул. Белинского, 58
}

Приведен комплексный анализ аварий в системах энергоснабжения в условиях Крайнего Севера как в сложных технических системах. На основе описаний аварий проанализированы причинь отказов, распределения времени восстановления систем энергетики. Время восстановления как показатель надежности предложено использовать для оценки тяжести отказов.

Ключевые слова: авария, водоснабжение, время восстановления, надежность, отказ, система энергетики Крайнего Севера, теплоснабжение, электроснабжение.

(C) Siberian Federal University. All rights reserved

* Corresponding author E-mail address: prokhorovdv@gmail.com 
Обеспечение эффективности и надежности систем энергоснабжения децентрализованных потребителей - острая нерешенная проблема в циркумполярных регионах. Задачи обеспечения энергетической безопасности регионов в зонах холодного климата более подробно обозначены в работе [1]. Надежность систем энергетики как составная часть безопасности определяется способностью непрерывного функционирования их элементов, сопротивляемостью возникающим аварийным ситуациям [2]. Одними из основных показателей надежности являются временные составляющие. Надежность энергетической системы зависит от времени ее восстановления после аварийной ситуации.

Анализ состояния надежности систем энергетики Севера рассматривается на примере Республики Саха (Якутия). Система энергоснабжения на Крайнем Севере состоит из систем электроснабжения и теплоснабжения. Каждая система в свою очередь состоит из подсистем. Для каждой подсистемы заданы определенные функции. Основными элементами системы электроснабжения являются система топливоснабжения, система генерации электроэнергии и система транспортировки электроэнергии, а теплоснабжения - система водоснабжения, система топливоснабжения, система выработки тепла и система транспортировки тепла. Все эти системы эксплуатируются в суровых климатических условиях, состоят из больших подсистем, их отказы вызывают значительные экономические потери для социальной среды.

Для анализа аварийных ситуаций в системе энергоснабжения республики были собраны материалы аварий, зафиксированных МЧС, и создана база данных [3]. Материал по авариям собран за период с 1998 по 2008 г. В описании аварий указано место происшествия, дата и время обнаружения. В некоторых случаях также указана причина аварии, количество пострадавшего населения, причиненный ущерб, время устранения аварии, наличие эвакуации населения. Для представления общей картины причин и последствий аварий в системах энергетики Крайнего Севера, ниже приводятся характерные описания аварий, произошедших в Республике Саха (Якутия).

1. В селе Тополиное 29 декабря 1998 г. из-за поломки глубинного насоса на водозаборе произошло промерзание водовода, в результате остались без тепла 42 жилых дома, 34 объекта соцкультбыта и 5 административных зданий. Пострадавшее население составило 1058 человек, в том числе 414 детей. Людей эвакуировали в пос. Хандыга.

2. В пос. Кысыл-Сыр 7 ноября 2002 г. по причине выхода из строя датчика контроля пламени произошла остановка парового котла. В результате аварии без централизованного тепло- и водоснабжения остались 105 квартир в 46 домах. Ущерб составил 5038,5 тыс. руб.

3. В пос. Тикси 6 февраля 2013 г. по причине отказа автоматики горелки Oilon-800 произошла остановка котла №1 марки «FR-10», при этом в работе остались два котла марки «ДКВР». Коммунальными службами горелка была заменена на форсунку «Р-200», но замена не дала нужного эффекта. С понижением температуры теплоносителя жителями был произведен слив воды из системы отопления. По причине массового слива теплоносителя произошло завоздушивание трубы, что привело к частичному нарушению теплоснабжения по стоякам отопления и холодного водоснабжения в девяти жилых домах. Ремонтные работы по отогреву стояков начались с 6 февраля и продолжались до полного восстановления теплоснабжения данных объектов до 12 февраля 2013 г. 
Из анализа аварий можно представить особенности и сценарии их развития. Под действием климатических факторов, сильного ветра может произойти падение опор электролиний, обрыв линий, короткое замыкание. Неисправность системы водоснабжения может произойти из-за утечки воды в теплотрассе, ограниченного количества воды в глубинной скважине, понижения уровня рек, замерзания водовода. Протяженность теплотрасс может составлять десятки километров. В условиях низких температур и в ночное время слив воды из трубопровода не всегда обеспечивает возможность предотвращения промерзания теплопровода. Низкая температура способствует промерзанию теплосети и быстрому понижению температуры зданий. На рис. 1 приведена гистограмма распределения отказов в системе энергетики по месяцам года. Как видно из данной гистограммы, интенсивность аварий повышается при низких температурах, т.е. в самые холодные месяцы отопительного зимнего периода (декабрь, январь).

Аварии в одном объекте, как правило, сопровождаются каскадным развитием, приводящим к массовому нарушению подачи энергии потребителям, и в совокупности повышают чрезвычайность аварийного события (табл. 1). В случае неблагоприятного воздействия одного или нескольких факторов происходит развитие аварии системы энергоснабжения, причем зачастую наблюдается синергетический эффект [4]: отдельное возмущение может не приводить к катастрофическим последствиям, но несколько в совокупности нарушают функционирование всей системы. В том случае, когда уровень живучести системы низкий и не удается во-

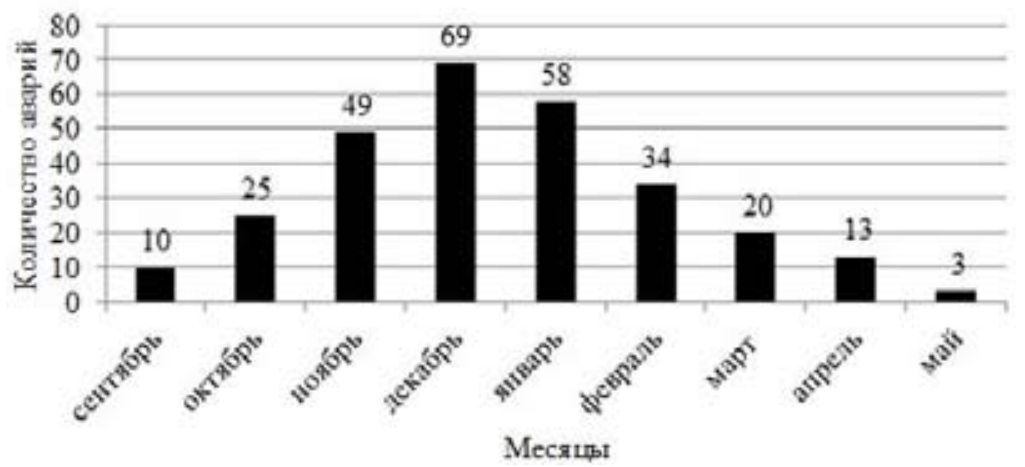

Рис. 1. Распределение аварий по месяцам

Fig. 1. Distribution of accidents by month

Таблица 1. Каскадное развитие аварий

Table 1. Cascading spread of accidents

\begin{tabular}{|l|c|c|c|c|c|c|}
\hline & Водоснабжение & $\begin{array}{c}\text { Электро- } \\
\text { снабжение }\end{array}$ & $\begin{array}{c}\text { Топливо- } \\
\text { снабжение }\end{array}$ & Котельная & $\begin{array}{c}\text { Тепловые } \\
\text { сети }\end{array}$ & Потребители \\
\hline Водоснабжение & 13 & & & & 3 & 7 \\
\hline Электроснабжение & 7 & 33 & & & 6 & 19 \\
\hline Топливоснабжение & & 3 & 11 & & 4 & 5 \\
\hline Котельная & & & & 79 & 19 & 47 \\
\hline Тепловые сети & & & & & 26 & 18 \\
\hline
\end{tabular}


время ввести резервы, авария принимает глобальный характер, распространяется на другие подсистемы. Наибольшее количество отказов имеет место в системе транспортировки тепла. Как видно, отказы обеспечивающих систем энергетики отражаются на надежности тепловых сетей. Следовательно, тепловые сети являются самым слабым звеном по надежности в системе энергетики Севера.

Время наработки на отказ как показатель надежности включает среднее время восстановления системы. Ниже приведены данные исследования по времени отказа систем энергетики при низких температурах. По данным отказов в системе энергоснабжения построены гистограммы времени восстановления при отказах системы теплоснабжения, системы электроснабжения и системы водоснабжения (рис. 2-4) за 2011-2015 гг. После анализа характеристика отказов по различным интервалам времени восстановления, построено распределение отказов для граничных значений времени: 6, 24 и 72 ч, что более соответствует характеру распределения температурного режима зданий при отказах.

Из данных статистики аварий видно, что наибольшее число отказов происходит из-за нарушений в системе электроснабжения. Однако их большая часть (около 90 \%) восстанавливает-

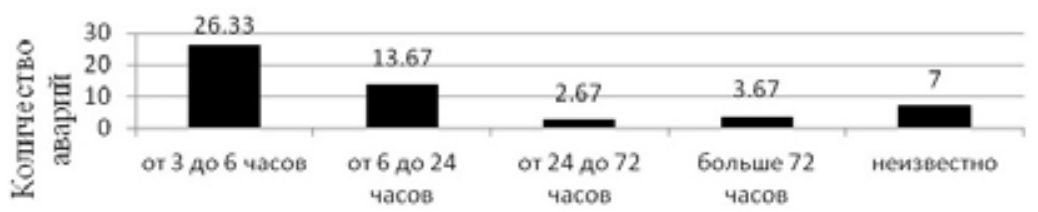

Время восстановления

Рис. 2. Время восстановления при отказе системы теплоснабжения

Fig. 2. Recovery time in case of heat supply system failure

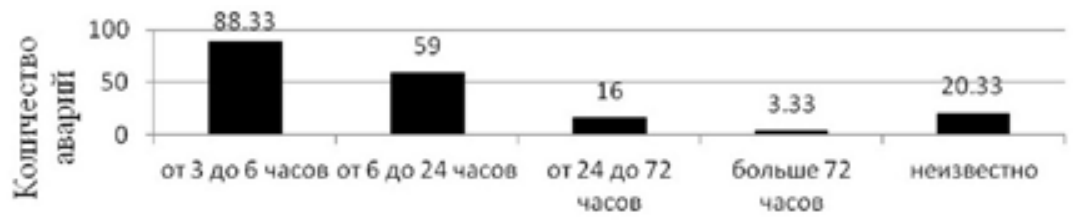

Время восстановленгя

Рис. 3. Время восстановления при отказе системы электроснабжения

Fig. 3. Recovery time in case of power supply system failure

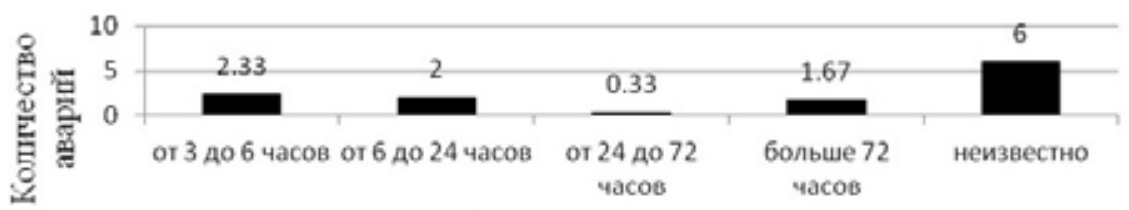

Времявосстановления

Рис.4. Вреамя восстановления при отказе системы водоснабжения

Fig. 4. Recovery time in case of water supply system failure 
ся в течение суток. Если в системе теплоснабжения и электроснабжения количество отказов по времени восстановления интенсивно снижается, то для отказов в системе водоснабжения отказы распределяются более равномерно по времени. Для первых двух систем в первые три часа восстанавливаются до $30 \%$ от всех отказов, за 6 ч - восстанавливаются более половины всех отказавших систем. За сутки восстанавливаются 80-90\% от всех отказов. В системе теплоснабжения за 6 часов восстанавливаются примерно 60 \% отказавших систем, за сутки - $86 \%$. Время восстановления за сутки примерно соответствует частичной потере качества теплоснабжения (рис. 1). Если время восстановления превышает одни сутки, то отказ приводит к полной остановке теплоснабжения. При отказах события «тепловой режим не нарушается» или «имеет место частичное снижение температуры в зданиях» в сумме занимают $90 \%$ от всех отказов. Те отказы, которые приводят к полной потере работоспособности, относятся к авариям, так как вызывают в основном продолжительные прекращения подачи энергии.

Надежность элементов системы энергоснабжения зависит от многих факторов, в том числе от климатических и человеческих, абсолютно устранить которые практически невозможно. Аварии и аварийные ситуации наблюдаются каждый год без исключения, и их динамика разнообразна. При низких температурах в системе энергетики имеет место каскадное распространение аварий. Самым слабым звеном по надежности в системе энергетики Севера является система транспортировки тепла. Важный показатель надежности при авариях энергетической системы при низких температурах - время введения системы в работоспособное состояние. Следовательно, время восстановления как показатель надежности можно использовать для оценки тяжести отказов.

\section{Список литературы}

[1] Махутов Н.А., Москвичев В.В., Фомин В.М. Создание техники северного исполнения проблема социально-экономического развития восточных регионов России, Вестник Российской академии наук, 2015, 85(2), 155-163 [Makhutov N.A., Moskvichev V.V., Fomin V.M. Northern Modification Mechanisms Creation - Problem of Social and Economic Development of Russian Eastern Regions, Herald of the Russian Academy of Sciences, 2015, 85(2), 155-163 (in Russian)].

[2] ГОСТ 27.002-89. Надежность в технике. Основные понятия. Термины и определения. М.: Изд. стандартов, 1990. 38 с. [GOST 27.002-89. Industrial product dependability. General concepts. Terms and definitions, Moscow, Publishing house of standards, 1990, 38 p. (in Russian)].

[3] Прохоров В.А., Иванов В.Н., Попова М.В. Проблема обеспечения безопасности системы теплоснабжения населенных пунктов Якутии, Безопасность труда в промышленности, 2009, 12, 49-52 [Prokhorov V.A., Ivanov V.N., Popova M.V. Safety Ensuring Problem of Heat Supply System in Settlements of Yakutia, Industrial safety in industry, 2009, 12, 49-52 (in Russian)].

[4] Попырин Л.С. Безопасность объектов теплоэнергетики, Теплоэнергетика, 1995, 9, 20-26 [Popyrin L.S. Heat Power Facilities Safety, Thermal Engineering, 1995, 9, 20-26 (in Russian)]. 